\title{
EXPLORING THE PROPERTIES OF LOCAL AND NON-LOCAL VERTICAL DIFFUSION SCHEMES IN THE EMEP MODEL USING ${ }^{222}$ RN DATA
}

\author{
A. Jeričevic ${ }^{1}$, H. Fagerli ${ }^{2}$ and B. Grisogono ${ }^{3}$ \\ ${ }^{1}$ Meteorological and Hydrological Service of Croatia, Zagreb, Croatia \\ ${ }^{2}$ Norwegian Meteorological Institute, Oslo, Norway \\ ${ }^{3}$ Andrija Mohorovicic Geophysical Institute, Department of Geophysics, Faculty of Science, University of Zagreb, Croatia
}

\begin{abstract}
The simulations of hourly Radon $222\left({ }^{222} \mathrm{Rn}\right)$ concentrations are performed with the Unified EMEP model (Simpson et al., 2003) in order to validate different parameterization schemes for vertical mixing. In addition to the recently evaluated (Jeričević et al., 2010) operational EMEP vertical diffusion schemes K(z), the non-local O'Brien (1970) and local Blackadar (1979) schemes, as well as the nonlocal Grisogono scheme (e.g. Grisogono and Oerlemans, 2002), a new scheme which is local in stable boundary layer (SBL) and non-local in convective boundary layer (CBL) and based on total turbulent energy (TTE) closure (e.g., Mauritsen et. al, 2007) is implemented in the EMEP model. Hourly measurements of the ${ }^{222} \mathrm{Rn}$ from different stations in Europe (the Cabauw tower in Netherlands, the Angus tower in Scotland, and Freiburg and Schauinsland in Germany) during the years 2005 and 2006 are compared to the corresponding modelled data.
\end{abstract}

Key words: higher order closure turbulence scheme, air quality modelling, Radon 222 measurements.

\section{INTRODUCTION}

The atmospheric boundary layer turbulence is the most important mechanism for the distribution of tracers. The parameterization of turbulent diffusion $\mathrm{K}(\mathrm{z})$ is an inevitable, traditional approach in description of turbulent processes and the estimation of turbulence effects in air quality models. Previous studies have already shown that the parameterizations of $\mathrm{K}(\mathrm{z})$ have significant impacts on simulated chemical concentrations (e.g. Oliviè et al., 2004). Various parameterizations, mainly first-order, non-local eddy diffusivity K schemes are proposed and widely used in practical applications (e.g. O'Brien, 1970; Holtslag and Moeng, 1991; Grisogono, 1995). A several modifications of the first-order schemes are proposed to overcome deficiencies to accurately simulate dispersion in different atmospheric stability conditions (e.g. Grisogono and Oerlemans, 2002; Mihailovic and Alapaty, 2007). In this paper, we evaluate the performance of the higher-order closure K scheme based on total turbulent energy (TTE) closure (e.g., Mauritsen et. al, 2007) in addition to recently evaluated schemes, the O'Brien, Blackadar and Grisogono schemes in the EMEP model (Jeričević et al. 2010). For the model evaluation available measurements ${ }^{222} \mathrm{Rn}$ from Europe are used.

Radon is a radioactive gas which is found naturally in trace amounts in most rocks and soils. Since radionuclide ${ }^{222} \mathrm{Rn}$ has a half-life of 3.8 days and it is emitted primarily from the continents at a fairly constant emission rate between 0.8 and 1.3 atom $\mathrm{cm}^{-2} \mathrm{~s}^{-1}$ (Dentener et al., 1999) it is ideal to study the model sub-grid mixing schemes, numerical advection schemes or to compare different models. A considerable number of global and regional studies have been devoted to the simulation of ${ }^{222} \mathrm{Rn}$ for different purposes (e.g. Lee and Larsen, 1997; Denetner et. al., 1999; Oliviè et al., 2004; Galmarini, 2006). In this work the simulations of ${ }^{222} \mathrm{Rn}$ are performed in order to validate vertical mixing schemes in the EMEP model and compare to available ${ }^{222} \mathrm{Rn}$ measurements in Europe during the years 2005 and 2006 . The hourly measurements of ${ }^{222} \mathrm{Rn}$ from the Cabauw tower in Netherlands, the Angus tower in Scotland, Freiburg and Schauinsland in Germany and Krakow in Poland are used. The goal of this work is to evaluate the model performance and to find the best $\mathrm{K}(\mathrm{z})$ parameterization scheme for the EMEP model as well as to better understand the behaviour of ${ }^{222} \mathrm{Rn}$ in relation to the meteorological conditions.

\section{MODEL AND METHODS}

Model

The Unified EMEP model (http://www.emep.int/) was developed at the Norwegian Meteorological Institute under the EMEP programme. The model is a development of the earlier EMEP models (Berge and Jakobsen, 1998), and is fully documented in Simpson et al. (2003). It simulates the atmospheric transport and deposition of acidifying and eutrophying compounds, as well as photo-oxidants and particulate matter over Europe. The model domain covers Europe and the Atlantic Ocean with the grid size $50 \mathrm{~km} \times 50 \mathrm{~km}$ while in the vertical there are 20 terrain-following layers reaching up to $100 \mathrm{hPa}$. The Unified EMEP models uses the 3-hourly meteorological data from PARallel Limited Area Model with the Polar Stereographic map projection (PARLAM-PS), which is a dedicated version of the HIgh Resolution Limited Area Model (HIRLAM) model for use within the EMEP. In this work the Unified EMEP model version rv2_6_1 was used. In the EMEP model emissions of ${ }^{222} \mathrm{Rn}$ are 1 atom $\mathrm{cm}^{-2} \mathrm{~s}^{-1}$ uniformly distributed over the continent.

\section{Description of K(z) parameterization schemes}

Vertical diffusion schemes, the O'Brien (1970) and Blackadar (1979) applied in convective boundary layer (CBL) and stable boundary layer (SBL) respectively, are called here the $\operatorname{OLD} K(z)$ scheme as they are operationally applied in the model. The OLD and Grisogono schemes (e.g. Grisogono and Oerlemans, 2002) are recently evaluated in the EMEP model (Jeričević et al., 2010). Empirical coefficients determined from LES data (DATABASE64; Esau and Zilitinkevich, 2006) in stable and neutral conditions are used in the Grisogono approach (Jericevic and Vecenaj, 2009).

In this work the description of a new $K(z)$ scheme, so called the total turbulent energy (TTE) scheme, based on a higher-order closure for neutral and stratified atmospheric conditions, is given. The TTE is the sum of the turbulent kinetic energy $\left(\mathrm{E}_{\mathrm{k}}\right)$ and turbulent potential energy $\left(\mathrm{E}_{\mathrm{p}}\right)$ which is proportional to the potential temperature variance. In unstable conditions the closure deploys only the TKE. Here we consider the TTE $(E)$ :

$$
E=E_{k}+E_{p}
$$


According to the TTE scheme vertical diffusion coefficient can be found from:

$$
K(z) \approx \frac{2 f_{\theta}^{2} E_{k} l}{C_{\phi} \sqrt{E}}
$$

where $f_{\theta}$ is the non-dimensional heat flux, $l$ is the dissipation length scale and $C_{\phi}$ is the empirical constant determined based on the LES data (Mauritsen et al., 2007).

\section{Statistical methods for air quality model evaluation}

It is important to properly evaluate air quality models in order to demonstrate their reliability in simulating the phenomena of interest as well as to properly test different parameterization schemes in model. Multiple performance measures are applied and considered as each measure has advantages and disadvantages and there is no single measure that is universally applicable to all conditions. In order to evaluate the predictions of a model with observations according to e.g. Wilmot (1982) and Chang and Hanna (2004) following statistical performance measures are used in this work: the correlation coefficient $(r)$, bias $(B I A S)$, mean absolute error $(M A E)$, mean square error (MSE), root mean square error (RMSE), fractional bias $(F B)$, the normalized mean square error (NMSE), systematic $\left(N M S E_{\_} s\right)$ and unsystematic $\left(N M S E \_u\right)$ and the index of agreement $(d)$. The best scheme is the one which gives the best model results. The best model performance has the highest $r$ and $d$, the lowest $B I A S, M A E, M S E, R M S E, F B$ and total NMSE, while better parameterization scheme should lower systematic errors in the model i.e. NMSEs values.

\section{RESULTS}

\section{Measurements}

In Fig. 1 normalized average monthly ${ }^{222} \mathrm{Rn}$ concentrations at Freiburg and Schauinsland during 2005, at the Angus and Cabauw towers and at Krakow during 2006 are shown. The normalized average concentrations range between $0.5 \mathrm{Bqm}^{-3}$ and $1.9 \mathrm{Bqm}^{-3}$. The seasonal pattern is characterized by an autumn maximum and spring minimum. On average, the seasonal maximum in September is found to be higher by a factor of 3 than the April minimum. The measured concentrations are normalized due to intercomparison reasons however there is a significant difference in average values. At the Cabauw at $20 \mathrm{~m}$ the average year concentration, $\bar{c}\left({ }^{222} R n\right)$, is $1.72 \mathrm{Bqm}^{-3}$, at $200 \mathrm{~m} \bar{c}\left({ }^{222} R n\right)=1.39 \mathrm{Bqm}^{-3}$ is found, while at the Angus measured concentrations are the lowest among all analyzed stations $\bar{c}\left({ }^{222} R n\right)=0.87 \mathrm{Bqm}^{-3}$. For Schauinsland $\bar{c}\left({ }^{222} R n\right)=2.17 \mathrm{Bqm}^{-3}$ is found, while at Freiburg and Krakow concentrations are the highest among analyzed stations with $\bar{c}\left({ }^{222} R n\right)=6.27 \mathrm{Bqm}^{-3}$ and $\bar{c}(222 R n)=6.0 \mathrm{Bqm}^{-3}$ respectively.

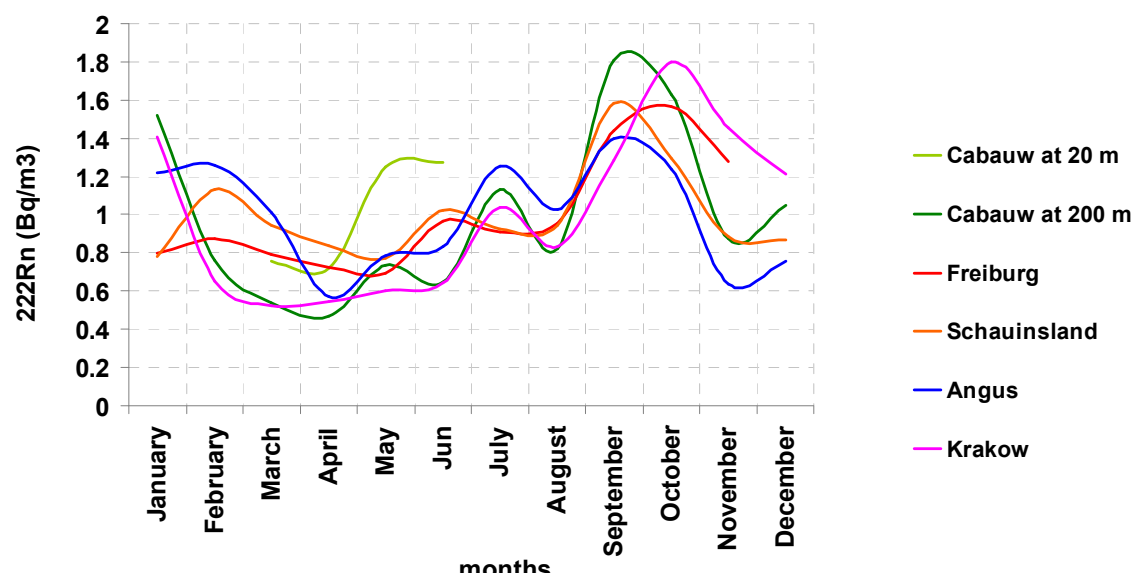

Figure 1. Normalized average monthly ${ }^{222} \mathrm{Rn}$ concentrations determined from measurements on the Angus tower in Scotland at $50 \mathrm{~m}$ height (blue line), the Cabauw tower in the Netherlands at $20 \mathrm{~m}$ (light green line) and $200 \mathrm{~m}$ (dark green line) heights, and in Krakow, Poland (pink

line) at surface during 2006 as well as in Freiburg at $300 \mathrm{~m}$ (red line) and Schauinsland at $1200 \mathrm{~m}$ (orange line) in Germany during 2005.

The evaluation of $\mathrm{K}(\mathrm{z})$ schemes performance

The results for FB, NMSE_S, NMSE $u$ and total NMSE are shown in Table 1, while $\mathrm{r}$ and $\mathrm{d}$ are in Table 2. There is a significant difference in model performance at different stations. The EMEP model performs almost perfect at the Cabauw tower with $F B$ nearly equal to zero and $N M S E \_s \approx 0$, while larger differences from the measurements are found at the Angus tower and Freiburg. The Grisogono scheme has the best performance at the Cabauw according to these measures. At Schauinsland the OLD scheme has slightly lower systematic error. The model has a good performance for mountain station Schauinsland. Since Schauinsland is only $8 \mathrm{~km}$ horizontal distance from Freiburg, and horizontal resolution in the model is $50 \mathrm{~km} \times 50 \mathrm{~km}$, the level closest to the height of the station is chosen as a representative for that mountain station. Results show that accuracy and systematic error in Schauinsland are low and that the chosen level is representative for the analyzed station.

It should be pointed that the NMSE is reduced with the Grisogono scheme at all stations. The TTE scheme, which managed to generate the highest ${ }^{222} \mathrm{Rn}$ concentrations in SBL conditions, improved results at Freiburg and Krakow. 
Index of agreement, $d$, which is a descriptive, relative and bounded measure, as well as for $r$ confirm that the best results are achieved with the Grisogono scheme at the Cabauw tower (Table 2).

Table 1. Fractional bias $(F B)$, systematic part of the normalised mean square error (NMSE $s$ ), unsystematic part of the normalised mean square error $(N M S E \quad u)$ and total normalised mean square error $(N M S E)$ calculated between the modelled and measured hourly ${ }^{222} \mathrm{Rn}$ concentrations $\left(\mathrm{Bq} \mathrm{m}^{-3}\right)$ for different stations: C-Cabauw tower at $200 \mathrm{~m}$, the Netherlands; S-Schauinsland, Germany; K-Krakow, Poland; FFreiburg, Germany and A-Angus tower, Scotland)

\begin{tabular}{|l|l|l|l|l|l|l|l|l|l|l|l|l|l|}
\hline & \multicolumn{4}{|l|}{ FB } & \multicolumn{4}{l|}{ NMSE_s } & \multicolumn{2}{l|}{ NMSE_u } & \multicolumn{2}{l|}{ NMSE } \\
\hline station & OLD & G & TTE & OLD & G & TTE & OLD & G & TTE & OLD & G & TTE \\
\hline C & 0.03 & -0.09 & -0.22 & 0.00 & 0.01 & 0.05 & 0.40 & 0.33 & 0.49 & 0.40 & 0.34 & 0.54 \\
\hline S & 0.37 & 0.39 & 0.38 & 0.14 & 0.16 & 0.15 & 0.45 & 0.51 & 0.54 & 0.60 & 0.67 & 0.69 \\
\hline K & 0.43 & 0.42 & 0.25 & 0.20 & 0.18 & 0.06 & 1.31 & 1.34 & 1.01 & 1.50 & 1.52 & 1.07 \\
\hline F & 0.55 & 0.52 & 0.37 & 0.32 & 0.29 & 0.14 & 0.51 & 0.51 & 0.47 & 0.83 & 0.80 & 0.61 \\
\hline A & -0.69 & -0.64 & -0.83 & 0.54 & 0.46 & 0.83 & 0.75 & 0.48 & 1.36 & 1.29 & 0.94 & 2.19 \\
\hline
\end{tabular}

Table 2. Same as Table 1 but for index of agreement (d) and correlation coefficient (r).

\begin{tabular}{|l|l|l|l|l|l|l|}
\hline & \multicolumn{2}{l|}{ Index of agreement (d) } & \multicolumn{4}{l|}{ Correlation coefficient (r) } \\
\hline station & OLD & G & TTE & OLD & G & TTE \\
\hline C & 0.84 & 0.86 & 0.8 & 0.73 & 0.76 & 0.69 \\
\hline S & 0.62 & 0.61 & 0.59 & 0.45 & 0.42 & 0.39 \\
\hline K & 0.57 & 0.55 & 0.63 & 0.21 & 0.12 & 0.32 \\
\hline F & 0.50 & 0.62 & 0.45 & 0.53 & 0.51 & 0.48 \\
\hline A & 0.41 & 0.37 & 0.50 & 0.48 & 0.60 & 0.46 \\
\hline
\end{tabular}

The model results at the Cabauw tower

In this section only measurements from the Cabauw tower are further analyzed. In Fig. 2 the time series of the observed hourly ${ }^{222} \mathrm{Rn}$ concentrations are plotted against the corresponding modelled ${ }^{222} \mathrm{Rn}$ concentrations calculated with three different K(z) schemes for the Cabauw tower during June, 2006. Agreement between the model and measurements is very good. The performance of the OLD and Grisogono schemes is similar while the local TTE scheme is able to capture the measured hourly peaks of concentrations $\approx 8 \mathrm{~Bq} \mathrm{~m}^{-3}$ and $6 \mathrm{~Bq} \mathrm{~m}^{-3}$, at $20 \mathrm{~m}$ and $200 \mathrm{~m}$ respectively during SBL conditions. From 1 to 14 June difference between the daily low concentrations during CBL conditions and the night-time higher concentrations during SBL conditions is obvious at $20 \mathrm{~m}$, while at $200 \mathrm{~m}$ the daily course of concentrations is not so pronounced. This regular daily course at $20 \mathrm{~m}$ is interrupted in period between the 15 and 18 June due to synoptical situation. However, it should be pointed that daytime mixing could be more intense to simulate the lower measured concentrations.
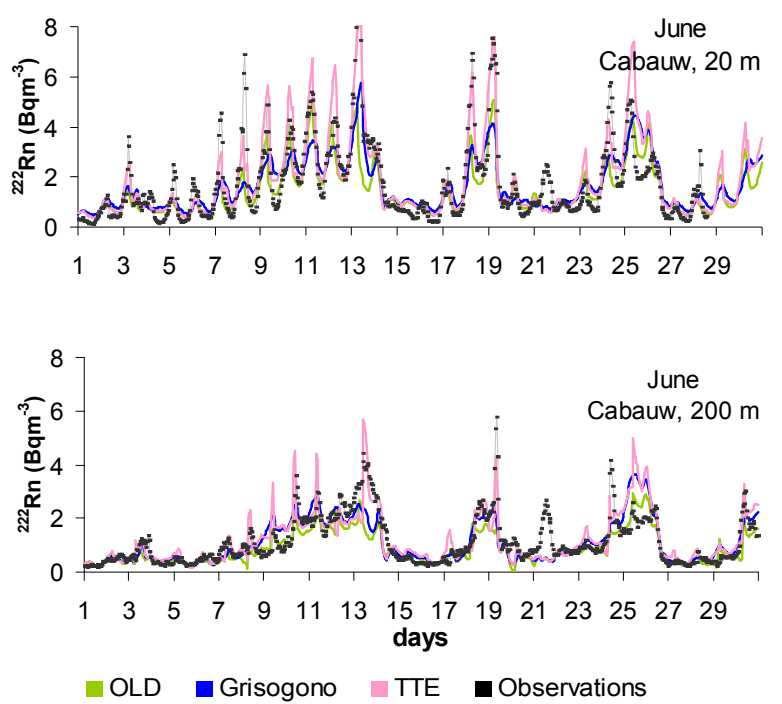

Figure 2. The hourly time series of the observed hourly ${ }^{222} \mathrm{Rn}$ concentrations (black dots) against the corresponding modelled ${ }^{222} \mathrm{Rn}$ concentrations calculated with three different K(z) schemes: the operational scheme OLD (green), the Grisogono scheme (blue) and the total turbulent energy scheme TTE (pink), at the Cabauw tower, the Netherlands during June, 2006.

In order to analyze the $K(z)$ schemes performance separately in stable and unstable conditions two different representative cases are chosen. The modelled hourly vertical $K(z)$ profiles and the corresponding vertical profiles of ${ }^{222} \mathrm{Rn}$ concentrations are investigated. The first case is from 10 to 11 June 2006 and it is chosen from the wormer part of the year when mainly CBL conditions prevail (Figs. 3a and 3b), and the second case is from 7 to 8 November 2006, in the colder part of the year when mainly SBL conditions prevail (Figs. $4 a$ and $4 b$ ). 
The Grisogono scheme produced lower mixing up to $100 \mathrm{~m}^{2} \mathrm{~s}^{-1}$, while much intensified mixing is produced with the OLD and TTE schemes reaching up to $400 \mathrm{~m}^{2} \mathrm{~s}^{-1}$ and $1400 \mathrm{~m}^{2} \mathrm{~s}^{-1}$ respectively during the first case in the daytime CBL conditions (Fig. 3a). On the other hand the non-local Grisogono scheme produced higher values of $K(z) \approx 6 \mathrm{~m}^{2} \mathrm{~s}^{-1}$ in the layer near the ground of $400 \mathrm{~m}$ thickness during the night-time SBL conditions (Fig 3a) while the local-schemes TTE and OLD i.e. the Blackadar scheme have negligible mixing $<0.5 \mathrm{~m}^{2} \mathrm{~s}^{-1}$. Note an occurrence of the intensified mixing with the TTE scheme (Fig 3a) at approximately $400 \mathrm{~m}$ which started to develop in the afternoon of $10^{\text {th }}$ June reaching its maximum value around midnight. Obviously the TTE scheme managed to reproduce a higher turbulence in the residual layer which was not visible with the other schemes. The corresponding concentrations for the summer case with different $\mathrm{K}(\mathrm{z})$ schemes are shown in Fig 3b. A daily course in concentrations is obvious. During SBL conditions, when the mixing is low, the accumulation of the surface ${ }^{222} \mathrm{Rn}$ concentrations occurs (yellow and red areas in Fig 3b). With the development of unstable conditions i.e. in CBL from $6 \mathrm{AM}$ to $14 \mathrm{PM}$ vertical transport is intensified, surface concentrations are diluted and higher concentrations are transported to higher levels. Neutral conditions prevail in the afternoon from 15 PM to 19 PM when the atmosphere is well mixed and the concentrations are uniformly vertically distributed. With the development of SBL nighttime conditions the accumulation starts again. Due to lower mixing in SBL concentrations produced with the TTE and OLD schemes are higher than those calculated with the Grisogono scheme. However, during CBL conditions with the Grisogono scheme concentrations are higher than with the other two schemes.
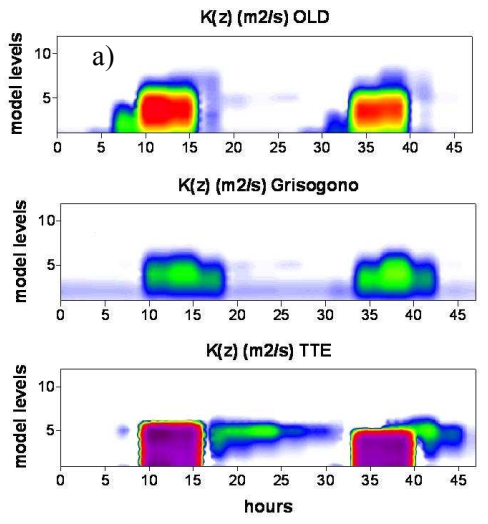

L 200400600800100012001400 $\left(\mathrm{m}^{2} \mathrm{~s}^{-1}\right)$
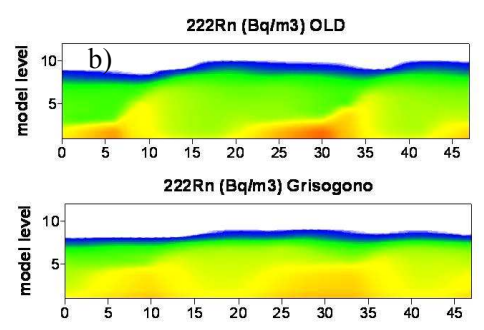
$222 R n(B q / m 3) T T E$

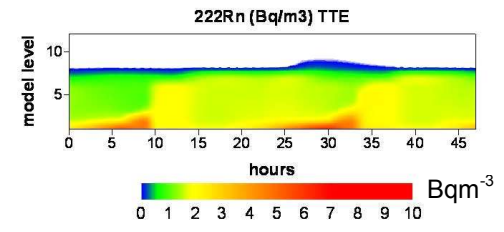

Figure 3. The modelled hourly vertical profiles for the unstable case during 10 th and 11 th June 2006 of a) $K(z)\left(\mathrm{m}^{2} \mathrm{~s}^{-1}\right)$ and b) ${ }^{222} \mathrm{Rn}$ with the OLD, Grisogono and TTE schemes, for the Cabauw tower.

The second case during 7 and 8 November 2006 is used to analyze $K(z)$ and ${ }^{222} \mathrm{R}$ profiles in the colder part of the year (Fig. $4 \mathrm{a}$ and $4 \mathrm{~b}$ ). The vertical mixing with all schemes is generally lower in November than in June, especially in the CBL. There is no clear difference between the night-time and day-time conditions particularly with the non-local Grisogono scheme which has $K(z) \approx 10 \mathrm{~m}^{2} \mathrm{~s}^{-1}$ (Fig. 4a). As a result higher surface ${ }^{222} \mathrm{Rn}$ concentrations are produced and mainly kept in the thin layer close to the ground (Fig 4b). Generally, the simulated surface ${ }^{222} \mathrm{Rn}$ concentrations are by a factor of two higher in November than in June (Fig. 4b). During the afternoon and through the night on 8 November 2006, i.e. from $38^{\text {th }}$ hour of the model run, the atmosphere was synoptically unstable due to cold front passage over the analyzed area.

\section{CONCLUSIONS}

The evaluation of the EMEP model and $K(z)$ parameterization schemes is based on ${ }^{222} \mathrm{Rn}$ data which are found to be a good tracer to study dynamical processes in the atmosphere. Simulations of ${ }^{222} \mathrm{Rn}$ with the EMEP model are performed during the years 2005 and 2006 and compared to the available ${ }^{222} \mathrm{Rn}$ measurements in Europe: the Cabauw and Angus towers, Freiburg, Schauinsland and Krakow. In addition to recently evaluated the OLD and Grisogono schemes (Jeričević et al., 2010), a new scheme which is based on total turbulent energy (TTE) closure (Mauritsen et al., 2007) is implemented in the EMEP model and analyzed. Intercomparison of different local and non-local schemes on the ${ }^{222} \mathrm{Rn}$ data showed that the non-local scheme Grisogono is less diffusive in CBL conditions than the O'Brien and TTE scheme. This is mainly because empirical coefficients used in the Grisogono scheme (Jeričević and Večenaj, 2009) are primarily developed for neutral and stable conditions based on LES data (DATABASE64; Esau and Zilitinkevich, 2006). The estimation of empirical coefficients for CBL conditions on the LES data is foreseen. The local schemes produce higher surface concentrations in SBL conditions, while the Grisogono scheme ${ }^{222} \mathrm{Rn}$ concentrations are dispersed over a thick layer $\approx 200 \mathrm{~m}$ and the resulting concentrations are lower near the surface. Non-local scheme, such as Grisogono, is highly dependent on model's vertical resolution, while in the local diffusion scheme $\mathrm{K}(\mathrm{z})$ is determined independently at each model level based on local vertical gradients. The present version of the EMEP model has the lowest level at $100 \mathrm{~m}$ which is an important deficiency for non-local $\mathrm{K}(\mathrm{z})$ schemes to properly simulate diffusion in SBL conditions. In order to evaluate the model predictions with observations and to estimate the performance of different $\mathrm{K}(\mathrm{z})$ schemes a set of statistical measures is used (e.g. Wilmot, 1982; Chang and Hanna, 2004).

Results of the model evaluation on ${ }^{222} \mathrm{Rn}$ data showed that the model has the best results for the Cabauw tower. The Cabauw tower is representative for the model evaluation due to its position in a flat terrain as well as due to uniform ${ }^{222} \mathrm{Rn}$ emission in the area. On the other hand data in Freiburg and Krakow are affected by the local natural emissions of ${ }^{222} \mathrm{Rn}$ while the Angus tower concentrations are dominated by the advection of ${ }^{222} \mathrm{Rn}$ free air from the sea (the emissions of ${ }^{222} \mathrm{Rn}$ are 100 times less over the sea than over the land). The highest concentrations are simulated with the TTE scheme and systematic error is decreased while accuracy in increased in the model for Freiburg and Krakow. For an appropriate description of ${ }^{222} \mathrm{Rn}$ 
distribution in the atmosphere, its response to the latitudinal, time and intensity variability of precipitation should be accounted explicitly (Galmarini, 2006). Since those variability's in radon natural fluxes are not included in the model certain deviations from observations are expected.
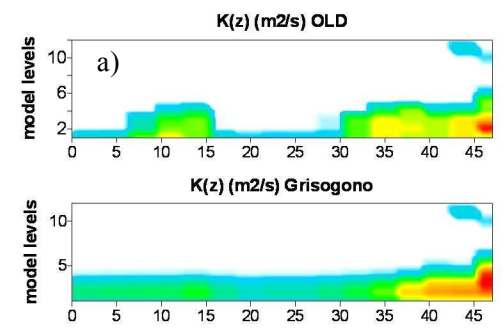

$K(z)(m 2 / s)$ TTE

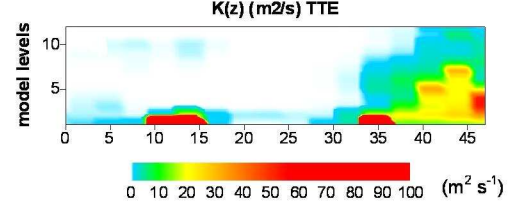

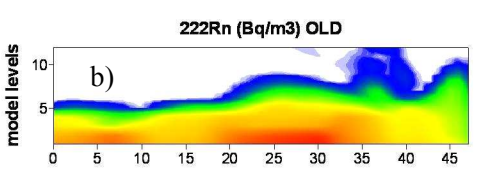
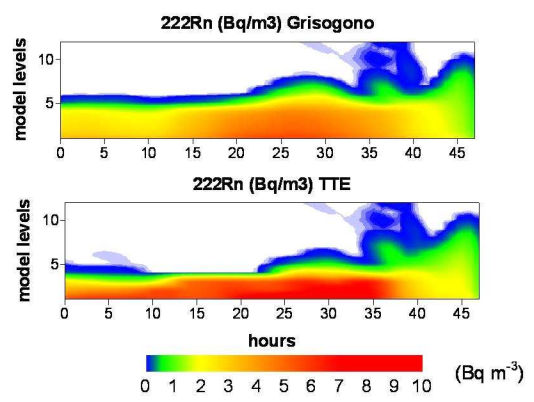

Figure 4. The modelled hourly vertical profiles for the stable case during $7^{\text {th }}$ and $8^{\text {th }}$ November 2006 of a) $K(z)\left(\mathrm{m}^{2} \mathrm{~s}^{-1}\right)$ and b) ${ }^{222} \mathrm{Rn}$ with the OLD, Grisogono and TTE schemes, for the Cabauw tower.

\section{ACKNOWLEDGEMENTS}

We are thankful for the Radon data to Alex Vermeulen and W. Zahorowski for the Cabauw data, to Hartmut Sartorius, Bundesamt für Strahlenschutz, Rosastr. 9, 79098 Freiburg in Germany for Freiburg and Schauinsland data, Miroslaw Zimnoch for the Krakow data and John Moncrieff for the Angus tower data. The work is partly supported by the Croatian Ministry of Science, Education and Sport under the project numbers BORA 119-1193086-1311, 004-1193086-3036 and 1191193086-1323

\section{REFERENCES}

Blackadar, A. K., 1979: Modeling pollutant transfer during daytime convection. In: Fourth Symposium on Atmospheric Turbulence Diffusion and Air Quality, AMS, Reno, NV, pp. 443-447.

Berge, E., and Jakobsen, H. A.: A regional scale multi-layer model for the calculation of long-term transport and deposition of air pollution in Europe, Tellus, 50, 205-223, 1998.

Chang, J.C., and Hanna, S.R.: Air quality model performance evaluation, Meteorol. Atmos. Phys., 87, 167-196, 2004.

Dentener, F., Feichter, J., and Jeuken, A.: Simulation of the transport of 222Rn using on-line and off-line global models at different horizontal resolutions: a detailed comparison with measurements, Tellus B, 51, 573-602, 1999.

Esau, I., and Zilitinkevich, S.: Universal dependences between turbulent and mean flow parameters in stably and neutrally stratified planetary boundary layers, Nonlinear Proc. Geoph. 13, 135-144, 2006.

Galmarini, S.: One year of 222-Rn concentration in the atmospheric surface layer, Atmos. Chem. Phys. 6, 2865-2887, 2006.

Grisogono, B.: A generalized Ekman layer profile within gradually-varying eddy diffusivities, Q. J. Roy. Meteorol. Soc., 121, 445-453, 1995.

Grisogono, B. and J. Oerlemans, 2002: Justifying the WKB approximation in pure katabatic flows, Tellus A, 54, 453-462.

Holtslag, A. A. M., and Moeng, C. H.: Eddy diffusivity and countergradient transport in the convective atmospheric boundary layer, J. Atmos. Sci., 48, 1690-1698, 2, 1991

Jeričević A., and Večenaj, Ž.: Improvement of vertical diffusion analytic schemes under stable atmospheric conditions, Boundary-Layer Meteorol., 131, 293-307 2009.

Jeričević, A., L. Kraljević, B. Grisogono, H. Fagerli, and Ž.Večenaj, 2010: Parameterization of vertical diffusion and the atmospheric boundary layer height determination in the EMEP model, Atmos. Chem. Phys., 10, 341-364, 2010.

Lee, H. N., and Larsen, R. J.: Vertical diffusion in the lower atmosphere using aircraft measurements of 222Rn, J. Appl. Meteorol., 36, 1262-1270, 1997.

Mauritsen, T., Svensson, G., Zilitinkevich, S., Esau, I., Enger, L., and Grisogono, B.: A total turbulent energy closure model for neutrally and stably stratified atmospheric boundary layers, J. Atmos. Sci., 64, 4113-4126, doi:10.1175/2007JAS2294.1, 2007.

Mihailovic D T, Alapaty K (2007) Intercomparison of two K-schemes: local versus nonlocal in calculating concentrations of pollutants in chemical and air-quality models. Environ Modell Soft 22:1685 - 1689

O'Brien, J. J.: A Note on the vertical structure of the eddy exchange coefficient in the planetary boundary layer, J. Atmos. Sci., 27, 1213-1215, 1970.

Oliviè, D. J. L., Van Velthoven, P. F. J., and Beljaars, A. C. M.: Evaluation of archived and off-line diagnosed vertical diffusion coefficients from ERA-40 with 222Rn simulations, Atmos. Chem. Phys., 4, 2313-2336, 2004.

Simpson, D., H. Fagerli, J. E. Jonson, S. Tsyro, P. Wind and J.-P. Tuovinen, 2003: The EMEP Unified Eulerian Model. Model Description. Technical Report EMEP MSC-W Report 1/2003, The Norwegian Meteorological Institute, Oslo, Norway.

Willmott, C.J.: Some comments on the evaluation of model performance, Bull. Am. Meteorol. Soc., 63, 1309-1313, 1982. 